\title{
Understanding Individual Personality Types and Their Effect on Team Dynamics in a Senior Design Project Course
}

\author{
P.B. Ravikumar \\ Professor, Mechanical and Industrial Engineering \\ University of Wisconsin, Platteville, WI
}

\begin{abstract}
Prospective employers expect graduating engineers to be knowledgeable in both scientific/technical and engineering management aspects. It is often a challenge to include engineering management content in a tightly packed engineering curriculum. The challenge must be met by carefully selecting key engineering management topics and implementing them across the curriculum. The Senior Design Project course in Mechanical Engineering at UWPlatteville is one course where there is a relatively better opportunity and relevance to address some engineering management topics. Engineering management or management for that matter is broad in scope and includes knowledge in many areas such as cognitive processes, social processes, and project management processes. The course focuses on teams undertaking real world industry projects wherein effective team dynamics is very important. Personality types of individuals greatly affect team dynamics. Understanding of personality types and their effect on team dynamics contributes to the knowledge of cognitive and social processes in engineering management. This paper addresses the topic of personality types of individuals and their effect on team dynamics in the Senior Design Project course. Students are helped to understand and find their individual personality type in a 4-Level Artisan-Idealist-Rational- Guardian model and in a more detailed 16-Level model. Students also learn how to utilize the knowledge and differences of personality types amongst individuals to enhance better team dynamics while managing and solving industry projects.
\end{abstract}

\section{The Need for Engineering Management for Engineering Students}

The American Society for Engineering Management defines Engineering Management as a unique discipline that uses engineering skills and knowledge in managing large scale projects. It links all other types of engineers from civil and mechanical to chemical and electrical in accomplishing organizational results through the leadership of knowledge-workers and the appropriate application of technology ${ }^{1}$. Prospective employers expect graduating engineers to be knowledgeable in both scientific/technical and engineering management aspects. It is often a challenge to include engineering management content in a tightly packed engineering curriculum. The challenge must be met by carefully selecting key engineering management topics and implementing them across the curriculum. Engineering management or management for that matter is broad in scope and includes knowledge in many areas such as cognitive processes, social processes, and project management processes. These complex relationships are been well known and have been and will be studied for years ${ }^{2}$. The Senior Design Project course in Mechanical Engineering at UW-Platteville is one course where there is a relatively better opportunity and relevance to address some of these engineering management topics. 
The Senior Design Project course focuses on teams undertaking real world industry projects wherein effective team dynamics is very important. Personality types of individuals greatly affect team dynamics. Understanding of personality types and their effect on team dynamics contributes to the knowledge of cognitive and social processes in engineering management. This paper addresses the topic of personality types of individuals and their effect on team dynamics in the Senior Design Project course. Students are helped to understand and find their individual personality type in a 4-Level Artisan-Idealist-Rational- Guardian model and in a more detailed 16-Level model. Students also learn how to utilize the knowledge and differences of personality types amongst individuals to enhance better team dynamics while managing and solving industry projects.

\section{Personality Types and Instruments for their Assessment}

The earliest rigorous work on personality types dates back to the work of Carl Gustav Jung (1875-1961)3. Isabel Briggs Myers (1897-1980), together with her mother Katherine Cooks Briggs, extended Jung's theory of personality types, adding two important aspects. These were the recognition of the existence and roles of the auxiliary processes and the addition of the Judging (J) and Perceiving (P) preference, ${ }^{4,6}$. Thus Jung's eight types $(2 * 2 * 2)$ were extended to the Myers-Briggs' sixteen types $(2 * 2 * 2 * 2)$. Sixteen "Myers-Briggs Type Indicators" (MBTI) arise from every possible combination of one selection from each pair of dichotomies as shown in Figure 1 (ISTP, ENTJ are two example types of the possible 16). The abbreviations E, I, S, N, $\mathrm{T}, \mathrm{F}, \mathrm{J}$, and $\mathrm{P}$ as shown will be used throughout this paper.

\begin{tabular}{|l|l|l|l|}
\hline Extroversion & $\mathrm{E}$ & Introversion & $\mathrm{I}$ \\
\hline Sensing & $\mathrm{S}$ & Intuition & $\mathrm{N}$ \\
\hline Thinking & $\mathrm{T}$ & Feeling & $\mathrm{F}$ \\
\hline Judging & $\mathrm{J}$ & Perceiving & $\mathrm{P}$ \\
\hline
\end{tabular}

Figure 1

The MBTI has been and continues to be used worldwide and is an instrument developed specifically as a tool for the general population, and is therefore inherently benign. As a founding principle, no one type is any better or worse than any other and the test candidate has the final say as to his or her type designation ${ }^{6}$. In its basic form, MBTI is a 93-item instrument used worldwide for psychological type classification and is available in many different languages. The MBTI has been around for over 60 years and has been used in a number of occupational settings. MBTI instrument intends to find an individual's preference to the four dichotomies mentioned above as follows ${ }^{7}$ : 
Putting attention and getting energy by spending more time

- in the outer world of people and things (E) or

- in the inner world of ideas and images (I)

Paying more attention to

- information that comes in through the five senses (S) or

- the patterns and possibilities seen in the received information $(\mathrm{N})$

Making decisions by putting more weight on

- objective principles and impersonal facts $(\mathrm{T})$ or

- personal concerns and the people involved (F)

Liking to live in a world of a more

- structured and decided lifestyle (J) or

- flexible and adaptable lifestyle (P)

The choice between $\mathrm{E}$ or $\mathrm{I}$ is about orientation, $\mathrm{S}$ or $\mathrm{N}$ is about cognitive perceiving function, $\mathrm{T}$ or $\mathrm{F}$ is about cognitive judging function, and $\mathrm{J}$ or $\mathrm{P}$ is about attitude of the functions. Myers stated that the interaction of these orientations, functions and attitudes are what makes up the personality types.

The Keirsey Temperament Sorter II (KTSII) is an instrument developed by David Keirsey ${ }^{8}$, a contemporary of Isabel Myers. The test is available online as a 70-item instrument that has only two possible responses for each item? ${ }^{9}$. Keirsey follows the MBTI tradition of using 16 types but condenses through a tree-like structure into four temperament groupings called Artisans, Idealists, Rationals, and Guardians. Fundamentally, Keirsey looks at the four possible combinations between abstract or concrete in communicating and cooperative or utilitarian in achieving goals. Artisans prefer concrete communication and utilitarian goal achievement traits, idealists prefer abstract and cooperative traits, rationals prefer abstract and utilitarian traits, and guardians prefer concrete and cooperative traits. Linkage of the four KTSII types to the sixteen MBTI types is another classification. Artisans prefer S and/or P, idealists prefer N and/or F, rationals prefer $\mathrm{N}$ and/or T, and guardians prefer S and/or J. Just like MBTI, KTSII is widely used in industry and education.

\section{Administering KTSII and gathering information from Senior Design Project Students}

Different ways of teaching the topic of personality types and enabling students to find out and reflect on their personality type are possible. The approach taken in the Senior Design Project course is to give out a Questionnaire shown in Figure 2 for each student to fill out first. As can be seen in the Questionnaire, Question I is answered by taking the KTSII test online and entering the result as per the test. The remaining questions II through $\mathrm{X}$ are answered as per the students' personal opinions. It can be seen that question II, III, VII, VIII, IX and X directly address the principles of Keirsey's classifications described above. Also, question IV, V, and VI address 
more-in depth aspects of Keirsey's classification of personality types. Finally, responses to questions VII, VIII, IX and X help compose the 16-level MBTI demographic information. Please note that administering questionnaires that involve human subject research in areas such as behavioral sciences or personality types will often require permission from appropriate authorities or committees. Maintaining anonymity will also be often a strict requirement.

\section{QUESTIONNAIRE}

\section{QUESTION I}

What is your Temparament (or personality type) as per the result of the test you took at keirsey.com? (Check one)

ARTISAN: IDEALIST:

RATIONAL:

GUARDIAN:

To each of the following questions II through X, select an answer that best describes you in your opinion:

QUESTION II: In communicating, are you (Abstract or concrete?)

QUESTION III: In achieving goals, are you (Cooperative or Utilitarian)?

QUESTION IV: What are you most proud of about yourself? (Select ONE from the following):
a. Of the degree to which you are graceful in action
b. Of the degree to which you are empathic in action
c. Of the degree to which you are competent in action
d. Of the degree to which you are reliable in action

QUESTION V: What do you respect the most about yourself? (Select ONE from the following):
a. Of the degree to which you do good deeds
b. Of the degree to which you are daring
c. Of the degree to which you are benevolent
d. Of the degree to which you are autonomous

QUESTION VI: What are you most confident of about yourself? (Select ONE from the following):
a. Of the degree to which you are strong willed
b. Of the degree to which you are respectable
c. Of the degree to which you are adaptable
d. Of the degree to which you are authentic

QUESTION VII: Are you more of an extrovert (E) or an introvert (I)? (E or I?)

QUESTION VIII: Do you notice information more by Sensing (S) or by intuition $(\mathrm{N})$ ? (S or N?)

QUESTION IX: Do you make decisions more by thinking (T) or by feeling (F)? (T or F?)

QUESTION X: Would you like to live in a world run more by judging $(\mathrm{J})$ or by perceiving $(\mathrm{P})$ ? (J or P?)

Figure 2 


\section{Representative Sample KTSII Test Results for Senior Design Project Students}

Results from KTSII test for one particular semester for a particular course section of students in the Senior Design project class are discussed next. It should be pointed out that the results are representative of results from past tests but several more tests in future semesters are planned to increase the rigor of the results and inferences from those results.

The results in Figure 3 below are for a group of 30 students in a particular semester section of the Senior Design Project course who took the KTSII test. The results are shown by a team-wise breakdown for team dynamics purposes besides composite results for the whole class.

\begin{tabular}{|rcccccccc|}
\hline & TEAM A & TEAM B & TEAM C & TEAM D & TEAM E & TEAM F & Total & \% \\
Artisans & 2 & 0 & 0 & 0 & 1 & 2 & $\mathbf{5}$ & $\mathbf{1 7}$ \\
Idealists & 1 & 0 & 0 & 0 & 0 & 0 & $\mathbf{1}$ & $\mathbf{3}$ \\
Rationals & 0 & 1 & 0 & 0 & 0 & 0 & $\mathbf{1}$ & $\mathbf{3}$ \\
Guardians & 2 & 4 & 5 & 6 & 3 & 3 & $\mathbf{2 3}$ & $\mathbf{7 7}$ \\
Total & & & & & & & & \\
Responses
\end{tabular}

Figure 3

The composite percentage demographics of Artisans, Idealists, Rationals, and Guardians shown in the extreme right column of Figure 3 is shown as a bar chart in Figure 4 below:

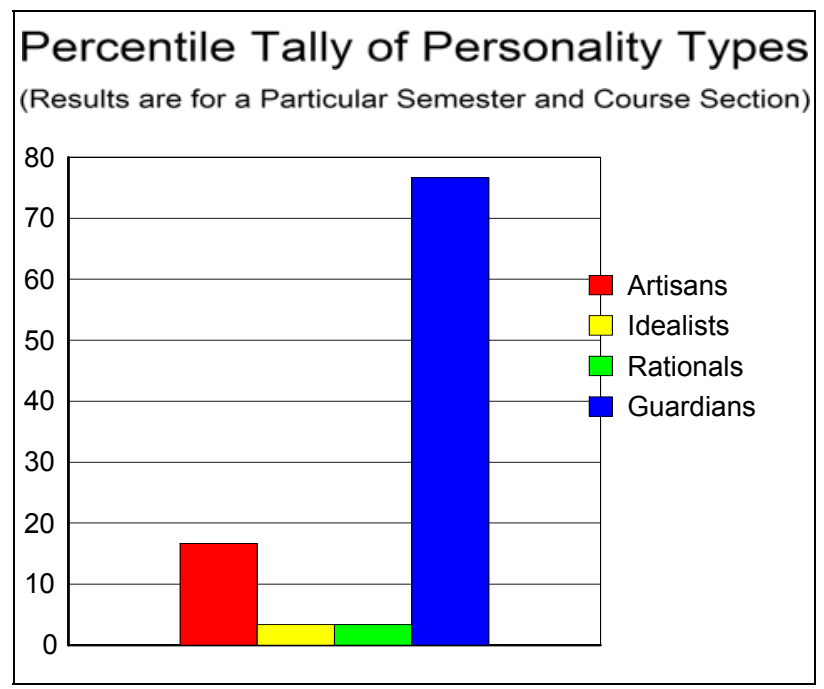

Figure 4

Besides the tally of raw KTSII test results shown in Figures 3 and 4 above, tallies have been of student responses to Questions II, III, VII, VIII, IX, and X and their comparison to assumptions of what those responses are through the underlying theory as described earlier for the KTSII personality type outcome. A sample for one team is shown in Figure 5 next. 


\section{Team A}

Students' Own Assessment

Member 1 Member 2 Member 3 Member 4 Member 5

Communicating: Abstract (A) or Concrete(C)

Achienving Goals: Cooperative(C) or Utilitarian(U)

Extrovert(E) or Introvert(I)

Sensing(S) or Intuition (N)

Thinking (T) or Feeling (F)

Judging $(\mathrm{J})$ or Perceiving $(\mathrm{P})$

Test's Assessment

Communicating: Abstract $(A)$ or Concrete $(C)$

Achienving Goals: Cooperative(C) or Utilitarian(U)

Extrovert(E) or Introvert(I)

Sensing(S) or Intuition (N)

Thinking $(\mathrm{T})$ or Feeling (F)

Judging $(\mathrm{J})$ or Perceiving $(\mathrm{P})$

Artisan (A) or Idealist (I) or Rational(R) or Guardian(G)

Test"s Prediction Accuracy

\section{Analysis of the Results}

$\begin{array}{rrrrr}\text { C } & \text { C } & \text { C } & \text { C } & \text { A } \\ \text { C } & \text { U } & \text { U } & \text { C } & \text { C } \\ \text { S } & \text { S } & \text { S } & \text { S } & \text { N } \\ & & & & \text { F } \\ \text { J } & \text { P } & \text { P } & \text { J } & \\ \text { G } & \text { A } & \text { A } & \text { G } & \text { I } \\ 75 \% & 75 \% & 75 \% & 25 \% & 50 \%\end{array}$

Figure 5

The raw number tally and hence the percentage tally of the four personality types show that a vast majority of graduating mechanical engineering seniors in the program are of the Guardian type $(77 \%$ in the sample). This has been the trend in past studies but more such studies are planned for the future to draw more robust conclusions. It has also been that the 20 to $40 \%$ balance of other types fluctuates between Artisans, Idealists, and Rationals. In the sample example, the $23 \%$ balance is made up of $17 \%$ were Artisans, $3 \%$ Idealists, and $3 \%$ Rationals. As for the test's prediction accuracy on detailed aspects such as responses to questions II and III, and two of questions VII through X, results vary from $25 \%$ to $100 \%$ bur rarely $0 \%$. It should be noted that just one wrong prediction drops the assessment by $25 \%$ as only responses to four questions are considered. Finally, as pointed out earlier, responses to Questions VII through X help gather information on the Meyers Briggs 16-level type categorization. For the sample in question, the results tallied as shown in Figure 6 which typifies a widespread distribution.

\begin{tabular}{|c|c|c|c|c|c|c|c|}
\hline ISTJ: 4 & ISFJ: 3 & INFJ: 1 & INTJ: 3 & ISTP: 4 & ISFP: 0 & INFP: 0 & INTP: 5 \\
\hline ESTP: 1 & ESFP: 0 & ENFP: 1 & ENTP: 1 & ESTJ: 2 & ESFJ: 0 & ENFJ: 0 & ENTJ: 5 \\
\hline
\end{tabular}

\section{Figure 6}

\section{Teaching/Learning Outcomes from the Study}


Students are given back their questionnaire after results are tallied. Anonymity of the responders is maintained even to the instructor because students only put their own secret password on the back of their questionnaire so that they can pick up their particular questionnaire. The 4-level personality types as per the KTSII theory and the 16-level personality types as per the MBIT theory are then discussed with the students. For example, the preference of Artisans to be concrete in communicating and utilitarian in achieving goals as well as their preference to sensing (S) and perceiving $(\mathrm{P})$ traits are shared with the students. As for the 16-level types, students are given handouts of the high-level description of the sixteen personality types and told to assess how the description for their particular type (such as ISTJ) matches their own understanding of their personality. For example, the description for ISTJ is as follows: "Serious and quiet, interested in security and peaceful living; essentially thorough, responsible, and dependable; well-developed powers of concentration; usually interested in supporting and promoting traditions and establishments; well-organized and hard working; work steadily

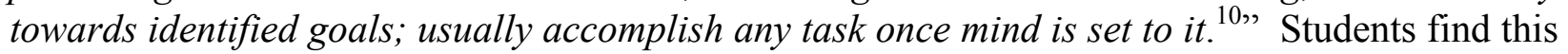
"personal-level" assessment to be very valuable and gain a respect for the scientific nature of the study. Students also learn that their demographics are not weighted very much towards any one particular type in the 16-level categorization but heavily weighted towards the Guardian type in the 4-level categorization. Students are apprised of the implications of that dominance. For example, an intuitive idea inference from other designs could help a project which may not be identified if the whole team has a preference only towards sensory information. The effect of personality types on team dynamics are also shared with the students. The helpful outcomes of the awareness of personality types on team dynamics are emphasized. For example, when the project manager is aware that his or her team is dominated by extroverts including the project manager himself or herself, it helps the project manager to play more of the role of listener (introvert) for better team meeting outcomes. It should be pointed out that it helps the instructor also to improve the teaching methods based on the personality type study. For example, a dominant group of Guardians means that they like a more ordered process of learning. This may require that more handouts be given to supplement the lectures for instance.

\section{Summary and Conclusions}

The Senior Design Project course in Mechanical Engineering at UW-Platteville is one course where there is a relatively better opportunity and relevance to address some engineering management topics. The course focuses on teams undertaking real world industry projects wherein effective team dynamics is very important. Personality types of individuals greatly affect team dynamics. Understanding of personality types and their effect on team dynamics contributes to the knowledge of cognitive and social processes in engineering management. This paper addressed the topic of personality types of individuals and their effect on team dynamics in the Senior Design Project course. Results from personality type tests in a 4-Level ArtisanIdealist-Rational- Guardian model and in a more detailed 16-Level model were gathered, analyzed, and inferences drawn. The study showed a dominance of Guardian personality type in the graduating mechanical engineering student group. How students utilize the knowledge and differences of personality types amongst individuals to enhance better team dynamics while managing and solving industry projects were also discussed. 


\section{Bibliography}

1 American Society for Engineering Management (ASEM) (n. d). Retrieved October 8, 2010 from https://netforum.avectra.com/eWeb/StartPage.aspx?Site=ASEM.

2 Meinhart, Wayne A. (1963). Artificial Intelligence, Computer Simulation of Human Cognitive and Social Processes, and Management Thought. The Academy of Management Journal, 9(4), 294-307. Retrieved October 8, 2010 from http://www.jstor.org/pss/254948.

3 Jung, C.G. (1971). Psychological types. In R.F.C. Hull, The collected works of Carl Gustav Jung, 6. Princeton University Press, Princeton, NJ. (Original work published in 1921).

4 Myers, I.B. \& Myers, P.B. (1995). Gifts Differing: Understanding Personality Types. Consulting Psychological Press, Palo Alto, CA.

5 Shen, Siu-Tsen, Prior, S.D., White, A.S., \& Karamanoglu, M. (2007). Using personality type differences to form engineering design teams. Engineering Education: Journal of the Higher Education Academy Engineering Subject Center, 2(2). Retrieved October 9, 2010 from http://www.engsc.ac.uk/journal/index.php/ee/article/viewArticle/63/99

6 Shen, Siu-Tsen, Prior, S.D., White, A.S., \& Karamanoglu, M. (2007). Using personality type differences to form engineering design teams. Engineering Education: Journal of the Higher Education Academy Engineering Subject Center, 2(2). Retrieved October 9, 2010 from www.engsc.ac.uk/downloads/scholarart/eejournal/.../shen st.pdf

7 The Myers \& Briggs Foundation (n.d.). Retrieved October 9, 2010 from http://www.myersbriggs.org/mymbti-personality-type/mbti-basics/

8 Keirsey, D. (1998). Please understand me II. Prometeus Nemesis Book Company, Del Mar, CA.

9 Take the KTS-II. Retrieved October 10, 2010 from http://keirsey.com/

10 High-Level Description of the Sixteen Personality Types. (n.d.). Retrieved October 19, 2010 from http://www.personalitypage.com/high-level.html 